\title{
Advanced Gas Tungsten Arc Weld Surfacing Current Status and Application
}

\author{
Stephan Egerland ${ }^{1}$, Johannes Zimmer ${ }^{1}$, Roland Brunmaier ${ }^{1}$, Roland Nussbaumer ${ }^{1}$, Gerhard Posch ${ }^{1}$, Bernd Rutzinger ${ }^{1}$ \\ ${ }^{1}$ Fronius International GmbH, Wels, Austria.
}

Received: 16 July, 2015

Accepted: 05 Oct., 2015

E-mail: egerland.stephan@fronius.com (SE)

\begin{abstract}
Gas Shielded Tungsten Arc Welding (GTAW) - a process well-known providing highest quality weld results joined though by lower performance. Gas Metal Arc Welding (GMAW) is frequently chosen to increase productivity along with broadly accepted quality. Those industry segments, especially required to produce high quality corrosion resistant weld surfacing e.g. applying nickel base filler materials, are regularly in consistent demand to comply with "zero defect" criteria. In this conjunction weld performance limitations are overcome employing advanced 'hot-wire' GTAW systems. This paper, from a Welding Automation perspective, describes the technology of such devices and deals with the current status is this field-namely the application of dual-cathode hot-wire electrode GTAW cladding; considerably broadening achievable limits.
\end{abstract}

Key-words: GTA weld cladding; Single-cathode GTAW; Hot-wire welding; Dual-cathode GTAW.

\section{Revestimento com GTAW Avançado: Estado da Arte e Aplicações}

Resumo: Gas Tungsten Arc Welding (GTAW) é um processo bem conhecido por proporcionar alta qualidade da solda mas juntas com menor desempenho. Por isto o Gas Metal Arc Welding (GMAW) é frequentemente escolhido para aumentar a produtividade, considerando que a qualidade é também amplamente aceitável. Segmentos da indústria, especialmente àqueles que requerem a produção de revestimentos resistentes à corrosão com alta qualidade, por exemplo, aplicando material de enchimento à base de níquel, estão regularmente sob consistente demanda para atender os critérios "zero defeito". Neste contexto, limitações na soldagem podem ser superadas com o emprego de sistemas avançados GTAW 'arame-quente'. Este artigo, sob a perspectiva da automação da soldagem, descreve a tecnologia de tais sistemas e apresenta o estado da arte nesse campo - principalmente quanto a aplicação do revestimento por GTAW com dois cátodos e arame quente, que amplia consideravelmente os limites alcançáveis do processo.

Palavras-chave: Revestimento por GTAW; GTAW cátodo único; Soldagem arame quente; GTAW cátodo duplo.

\section{Introduction}

Arc welding, to the widest extent, is suggested utilised for fusion welding. The major remainder; i.e. weld surfacing, is supposed reasonably split into 'hardfacing' and 'corrosion resistant' weld overlay [1,2]. Economic considerations drive manufacturers to apply high performance weld surfacing processes, such as Submerged Arc Welding (SAW) or Resistance Electro Slag Welding (RESW). Although producing broadly acceptable quality, these processes are specifically limited respectively due to compulsory use of flux (limited out-of-position capabilities), high dilution, or undesirable aspect ratios.

Controlled Gas Metal Arc Welding processes (e.g. CMT), have been introduced to the industry coping with dilution related issues, e.g. corrosion [3] and thereby partially replacing SAW and RESW. Surfacing applications exist, however, defining 'zero defect' criteria paramount to prevent complicated rework, sustainably assure highest weld surfacing performance and maintaining long-term component durability. Though joined by limited performance in arc efficiency and weld deposition rate Gas Shielded Tungsten Arc Welding (GTAW) is frequently applied in such cases. To overcome lack of performance, systems have been developed modifying the wire feeding process hereby leading to either 'cold-wire' or 'hot-wire'-GTAW. While the former was early revealing process instabilities and noticeably rather difficult deployable [4,5]; the latter appeared capable of tackling inconsistencies, mainly, by preheating the wire.
This is an Open Access article distributed under the terms of the Creative Commons Attribution Non-Commercial License which permits unrestricted non-commercial use, distribution and reproduction in any medium provided the original work is properly cited. 
Manz [6] early described the advantages e.g. a significant increase in weld deposition rate through beneficially using the resistive $I^{2} R$ wire heating and, compared with cold-wire GTAW, hereby achieving wire feed rates "3 to 10 times faster" into the weld pool [4]. Hot-wire GTAW systems continuously advanced, are nowadays well-accepted because of providing user benefits $[2,7,8]$. Information on the operational relationship applying 'hot-wire' and 'cold-wire' GTAW is given in [6] and according to this author proper parameter set up would even allow to deposit the wire without any additional arc. This is due to electrical resistive heating of the wire of a specific composition and diameter according to Equation 1 [6]:

$$
I^{2} R=I^{2} L \rho / d^{2}(\pi / 4)
$$

where $\rho$ is the apparent resistivity of the wire material, $L$ is for the effective wire extension length and $d$ is the wire diameter. The energy required for melting the wire can be expressed as Equation 2:

$$
E_{m e l t}=H F \delta d^{2}(\pi / 4)
$$

where $H$ is the heat content of the liquid wire volume, $F$ is the wire feed rate and $\delta$ is the apparent wire density.

Figure 1 adopted from [6] schematically depicts the hot-wire GTAW principle and Table 1 provides information to numbers and denotations used in Figure 1.

Wire feed rate $\mathrm{F}$ can be computed as Equation 3:

$$
F=I^{2} L(E S) /\left(\pi d^{2} / 4\right)^{2}
$$

ES is here referred to as the "extension sensitivity constant" [6] dependent only on the wire material composition. Correspondingly solving for the wire extension length, $L$ leads to Equation 4 :

$$
L=F\left(\pi d^{2} / 4\right)^{2} / I^{2}(E S)
$$

ES can be derived from Equation 5:

$$
E S=\rho / H \delta
$$

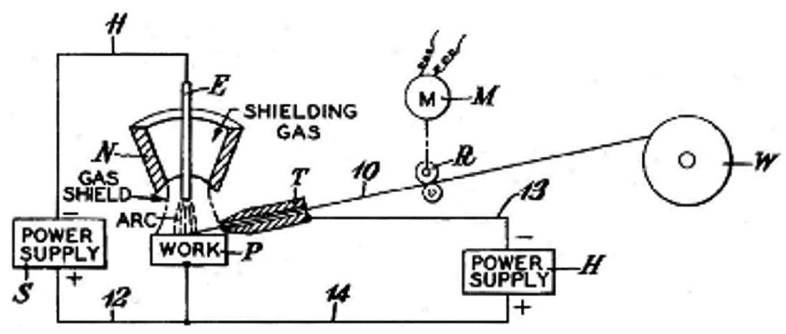

Figure 1. Schematic hot-wire GTAW system. After [6].

Table 1. Denotations and numbers in Figure 1.

\begin{tabular}{clccl}
\hline N & \multicolumn{1}{c}{ Shield gas nozzle } & R & Feed rolls \\
E & Tungsten electrode & S & GTAW power supply (CC mode) \\
W & Wire reel & $\mathbf{T}$ & Contact tube \\
$\mathbf{H}$ & Hot-wire power supply (CV mode) & $\mathbf{1 0}$ & Filler wire \\
$\mathbf{M}$ & Wire feed motor & $\mathbf{1 1 - 1 4}$ & Welding leads \\
\hline
\end{tabular}


The apparent resistivity, $\rho$, i.e. the difference between melting- and room temperature resistivity, can be approximated as Equation 6:

$$
\rho=\rho_{\text {melt }}-\rho_{\text {ambient }} / \ln \left(\rho_{\text {melt }} / \rho_{\text {room }}\right)
$$

while the apparent wire material density $\delta$ can be obtained from Equation 7:

$$
\delta=\delta_{\text {melt }}-\delta_{\text {ambient }} / \ln \left(\delta_{\text {melt }} / \delta_{\text {ambient }}\right)
$$

According to [6], ES is proportional to the $I^{2} R$ deposition rate value; thus, higher resistant wires comparably provide higher deposition rate vs. lower resistivity electrodes.

Due to mechanised wire feeding cold-wire GTAW provides relatively high deposition rates. Frequently joined by instabilities in supplying the wire electrode into the molten pool, however, it may cause irregular wire melting. Chilling phenomena are observed, degrading process stability and weld joint quality, regardless of whether the wire enters the melt pool either from the leading- or trailing edge. The arc is required to melt both the base- and the filler material which increases the risk for producing irregular weld beads.

Electrode preheating in hot-wire GTAW makes a considerable part of arc power unneeded to melt the wire. Maintaining an appropriate angle to enter the weld pool $\left(0^{\circ} \leq 30^{\circ} \leq 60^{\circ}\right)[4]$ the wire can be beneficially located at the trailing edge, close to, but not directly interacting with the arc [5].

More recent developments eliminate the second power supply by involving two electronic current control circuits. The first of which provides constant voltage characteristics for filler wire heating, and the second circuit board provides constant current characteristics output for controlling the arc current [8]. Although claiming to significantly reduce the amount of equipment regularly needed for hot-wire GTAW, it remains unknown to the authors whether such machines have obtained considerable industrial application. Especially for weld surfacing application that can prove advantageous over cold-wire GTAW because of both reducing penetration depth and dilution as to maintain process stability.

For hot-wire welding Goldsberry [9] presumes that this technology in general has found just limited industrial application since invented in the 1960's. Hence specific studies were mainly conducted to understand phenomena connected to improving productivity, e.g. by involving two wires inductively heated and successfully electromagnetically controlling the weld pool volume in out of position fusion welding [10]. Hori et al. [11], have studied magnetic arc blow phenomena well-known a major issue in employing hot-wire GTAW technology. The authors, who have developed a system to apply high frequency $(50-150 \mathrm{~Hz})$ pulsed current for pre-heating the wire, could overcome instabilities ("arcing") caused by electromagnetic fields induced by the gas shielded tungsten arc and acting on the wire as soon as being detached from the work piece. Ueguri et al. [12] have tried to assess the optimum relation between welding current and melting rate using parts of the arc heat for wire pre-heating. An increase of weld travel speed was found mainly permitted by the enlargement of the weld pool width; weld current was found limiting the wire feed rate, following an almost linear relationship with the wire heating current. Also for fusion welding application Yamamoto et al. [13] have developed an "ultra-high-speed" hot-wire GTA welding process. To achieve high weld travel speed and acceptable quality it was found that the wire pre-heating temperature is the most important parameter. Directly related to [13], Shinozaki et al. [14] have thoroughly studied phenomena caused by either the wire temperature and arc thermal input. The authors concluded that filler wire melting is mainly affected by wire pre-heating temperature and parent material melting is mainly caused by the welding arc.

\subsection{Hot-wire GTA Weld cladding automation}

Welding Automation beneficially contributes in raising productivity and efficiency, even when employing single hot-wire GTAW surfacing. Advanced equipment, Figure 2, can be used e.g. for internal and external GTAW cladding application.

Separately feeding 2 (two) electrically insulated wires to the weld pool produced by 1 (one) tungsten electrode, successfully increases productivity. Appropriate welding torches suitable for automated internal (a) or external (b) hot-wire GTAW weld overlay have been developed for industrial application and overcome 'single wire' limitations [2]. Applying such equipment allows to economically weld clad heavy components and simultaneously meet highest quality requirements; i.e. 'zero defect' criteria along with providing low dilution ratios. 


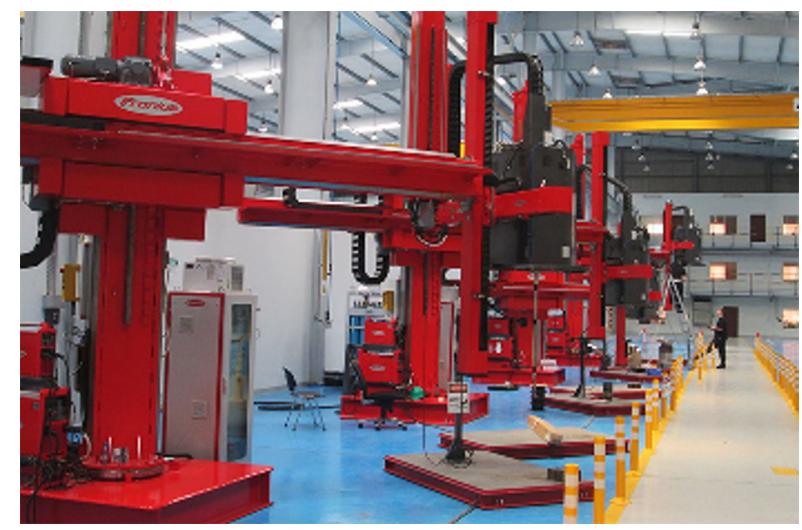

Figure 2. Endless Torch Rotating ETR ${ }^{\circledR}$ GTAW cladding systems lined up for internal borehole GTA weld cladding.

\subsection{Multi-cathode GTAW}

Increasing GTAW performance or weld deposition rate is regularly joined by increasing weld current, rising arc force or arc pressure, respectively $[15,16]$. The latter again is susceptible to cause weld defects, such as undercut or bead humping [17]. To cope with these limitations Yamada in the late 1990's [18] developed and patented [19] a novel high-efficiency GTAW method. Both electrodes, independently operated by two power supplies and electrically insulated to each other are paired in one weld torch. Feeding hot-wire to the weld pool allows for increased weld performance; i.e. weld deposition rate e.g. in producing large 9\% Ni-steel storage tanks [20]. Electrode geometry and adjustment are stated among the specifics of this method. Multi-cathode GTAW, Figure 3a, has early been tested to improve both process efficiency and weld quality.

Norrish [21] describes multi-cathode GTAW capable of significantly increasing weld travel speed and, by elongating the weld pool, preventing weld defects such as undercut. Figure $3 \mathrm{~b}$ plots weld travel speed over current in deploying single and multi-cathode GTAW. Considerable differences become noticeable through beneficially raising the number of cathodes. Undesirable but possible arc deflection between the electrodes is overcome by e.g. employing high-frequency pulsing or magnetic arc stabilisation [21].
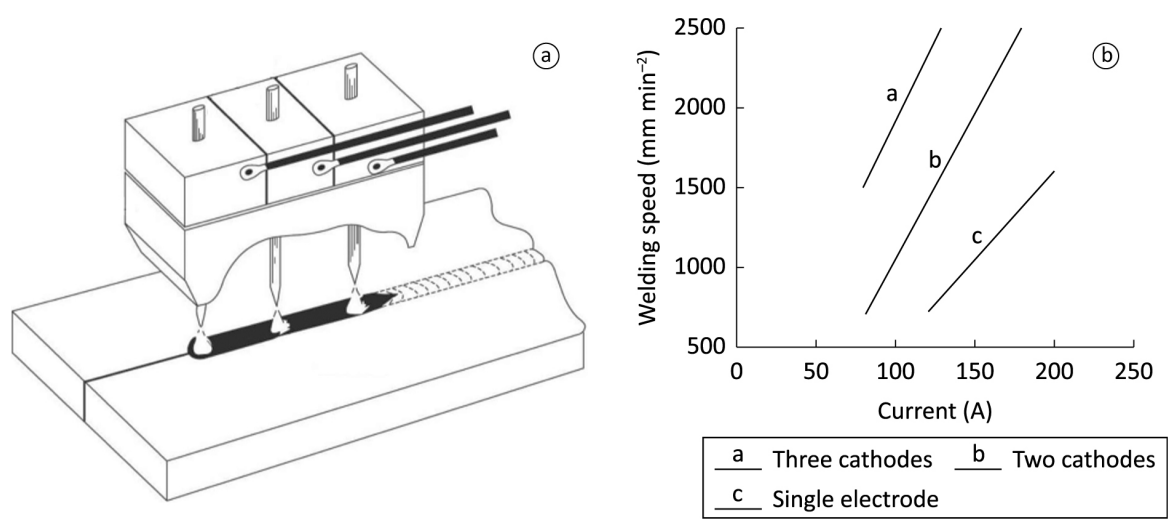

Figure 3. (a) Schematic multi-cathode GTAW and (b) comparison of weld travel speed. Note for (b) complete penetration weld application of AISI 304stainless steel wire ( $\varnothing 1.2 \mathrm{~mm}$ ). After Norrish [21].

\subsection{Dual-cathode GTAW}

Zhang et al. [22] studied the physical phenomena of "Twin tungsten TIG"; i.e. GTAW employing two electrodes in one welding torch. The authors suggested the Lorentz force to attract both arcs hereby forming a single arc whose pressure gradient is considerably lower vs. a single electrode GTAW process. 
The attracting force $\mathrm{F}$ can be calculated as follows (Equation 8) [22]:

$$
F=k \frac{I_{1} I_{2}}{L}
$$

$k$ is a constant, $I_{1}$ and $I_{2}$ respectively is the weld current for cathode 1 and cathode 2 and $L$ is the distance between both electrodes. $F$ is proposed increasing with rising current $/$ and decreasing with rising distance $L$. It was attempted to evaluate these relationships and the resulting phenomena effects especially on arc pressure. It was found the latter decreases in dual-cathode GTAW due to a broader area covered by the coupled arc approaching an elliptic cross section.

Figure 4a, adopted from [23], for single-cathode welding reveals the arc pressure steeply rising at the arc centre with increasing currents. Figure $4 \mathrm{~b}$ again, for dual-cathode GTAW shows the pressure level flattened and more broadly distributed around the arcs attracted.
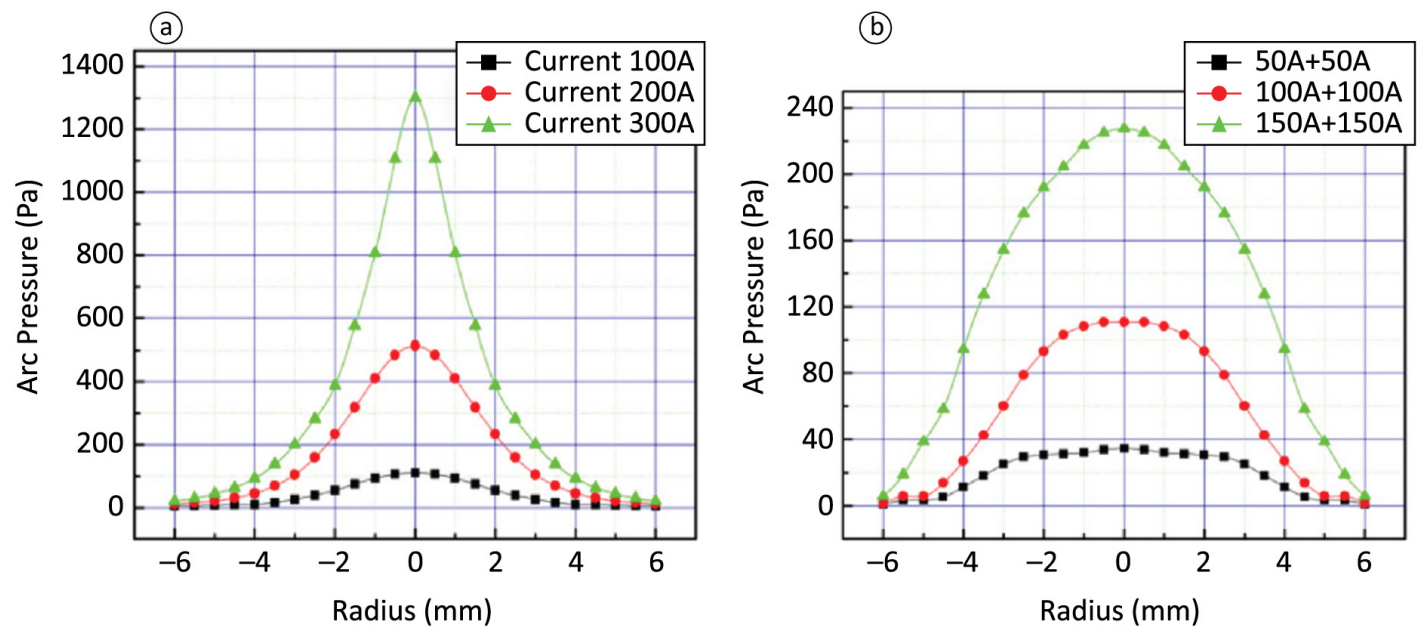

Figure 4. (a) Arc pressure measured for single and (b) dual-cathode GTAW. Note differently scaled y-axes. After [23].

Weld surfacing in general requires low dilution rates to maintain the deposited weld metal properties, e.g. corrosion resistance; weld pool depression again is considered a function of weld current height [16]. Leng and co-workers [23] connected to the work of [22] have thoroughly studied the relationships between current height and its influence on arc pressure distribution in dual-cathode GTAW. They found the latter decreased vs. similar values of current in single-cathode welding.

Assuming the major arc force mainly arising from the plasma jet impinging on the anode surface, according to [23] the arc pressure can be derived from the law of momentum conservation (Equation 9):

$$
P=\frac{1}{2} \xi v^{2}
$$

here, $P$ is the arc pressure, $\xi$ is the elemental plasma density and $v$ its velocity.

Using Maecker's [24] approach of relating the highest velocity ' $v c^{\prime}$ to the maximum current density, located at the arc centre, and assuming the plasma flow as "incompressible and inviscid" (Equation 10):

$$
v_{c}=\sqrt{\frac{u_{0} I j}{2 \pi \xi}}
$$

where $u_{0}$ is the magnetic permeability of free space and $j$ denotes the current density; one finally can achieve the relationship between arc pressure $P_{c}$ and $j$ in the arc centre line [24] (Equation 11): 


$$
P_{c}=\frac{u_{0} I j}{4 \pi}
$$

representing the arc pressure as directly proportional to current, $I$ or current density, $j$, respectively.

Applying expression (8), indicating the force attracting the arcs towards the centre, one can see the arc pressure increasing in the centre with rising arc currents or decreasing distance between the two cathodes employed. However, due to the split cathodes, both arcs are displaced from the centre, thus, likewise shifting the pressure maxima. According to [23] the force of attraction produces an arc overlapping, however, the resulting peak pressures are located off the centre and hence the final "coupling arc" pressure is dropped vs. each single or "overlapping arc".

Figure 5a shows the visible arc appearance of a dual-cathode setup for $200 \mathrm{~A}$ total current and Figure 5b graphically plots the comparison of the distinct arc pressures produced.
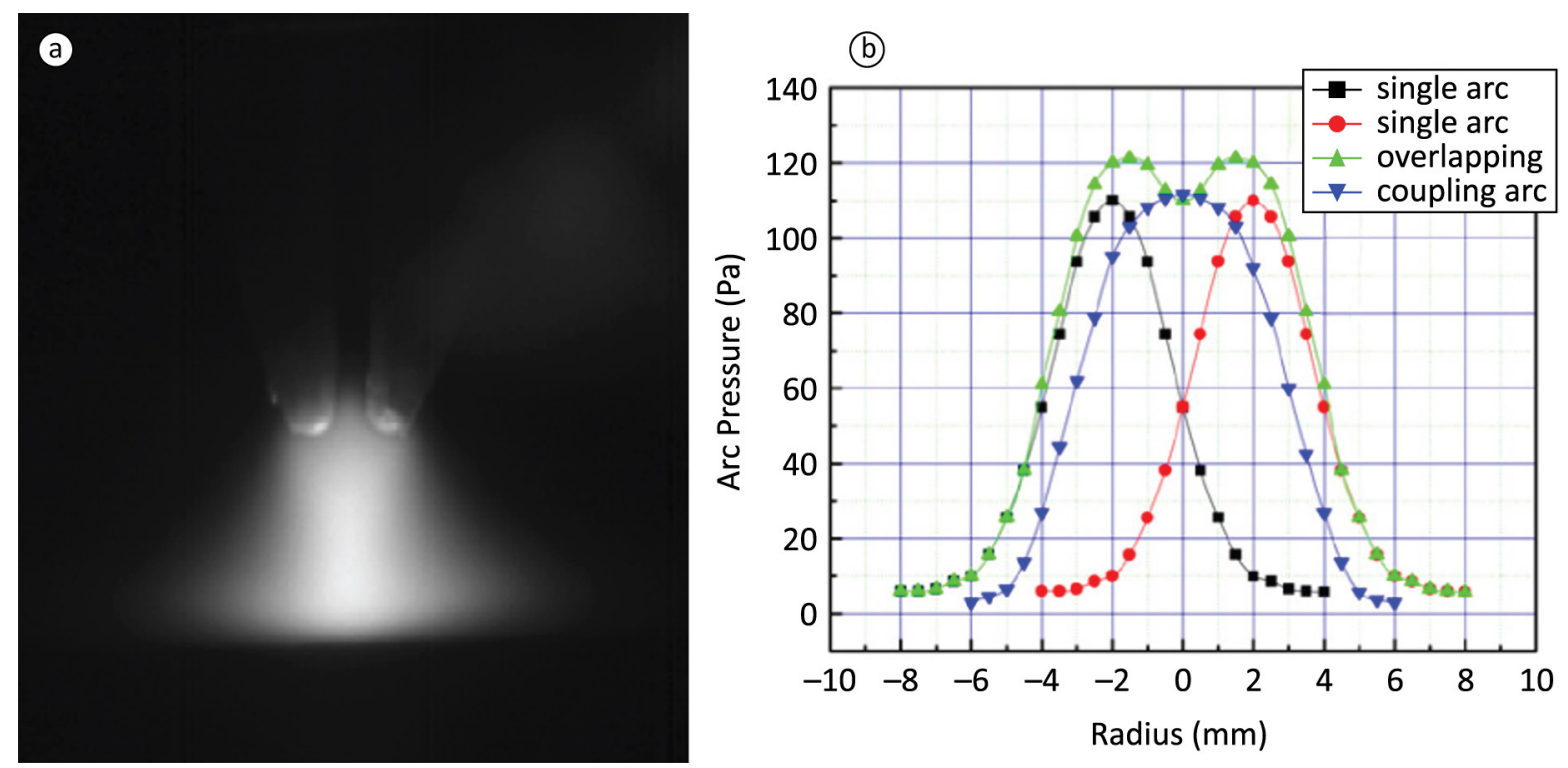

Figure 5. (a) Visible overlapping of $2 \times 100$ Ampere arcs and (b) comparison of single- overlapping- and coupling arc pressures for $2 \times 100$ Ampere arc current. After [23].

In a later work Zhang et al. [25] have applied the Fowler-Milne method to determine temperature distribution profiles in dual-cathode GTAW incorporating the influence of current, arc length and spatial electrode distance. Temperature maxima were found in the centre between both cathodes and current was evaluated increasing the temperature. Arc length was hardly affecting peak temperature but given the experimental setup, it was extending temperature distribution at the anodes. Wider cathode clearance was estimated decreasing the arc centre temperature. Martins [26] developed a dual-cathode welding torch based on commercial components for studying beneficial effects in preventing defects such as bead humping and undercut while simultaneously increasing process performance.

\section{Motivation}

As aforementioned weld current plays a major part in order to increase process efficiency. Knowing dual-cathode GTAW applicable to beneficially preventing from weld defects at higher currents it was aimed at developing an automation GTAW clad system upon dual tungsten cathode technology. 


\subsection{Dual-cathode welding torch development}

Severe arc interference can occur between both electrodes, capable of finally leading to process abortion due to cathode damage [26]. One of the most substantial technical requirements to meet in dual-cathode GTAW is highly precise and industrially practicable adjustment of both tungsten cathodes in one single weld torch. Arc interaction between both cathodes has to be assured sustainably suppressed, even for long lasting automated application, such as GTA weld cladding. Finally, the development of components easily adaptable to automation hardware already available, such as the $\mathrm{ETR}^{\circledR}$ GTAW cladding system, was considered another essential target to achieve.

Figure 6 schematically shows the developed novel type dual-cathode weld torch head basically employed for fully mechanised single hot-wire (a) or optionally twin hot-wire (b) GTAW application, the latter to further enhance weld deposition rates thus raising weld travel speed.

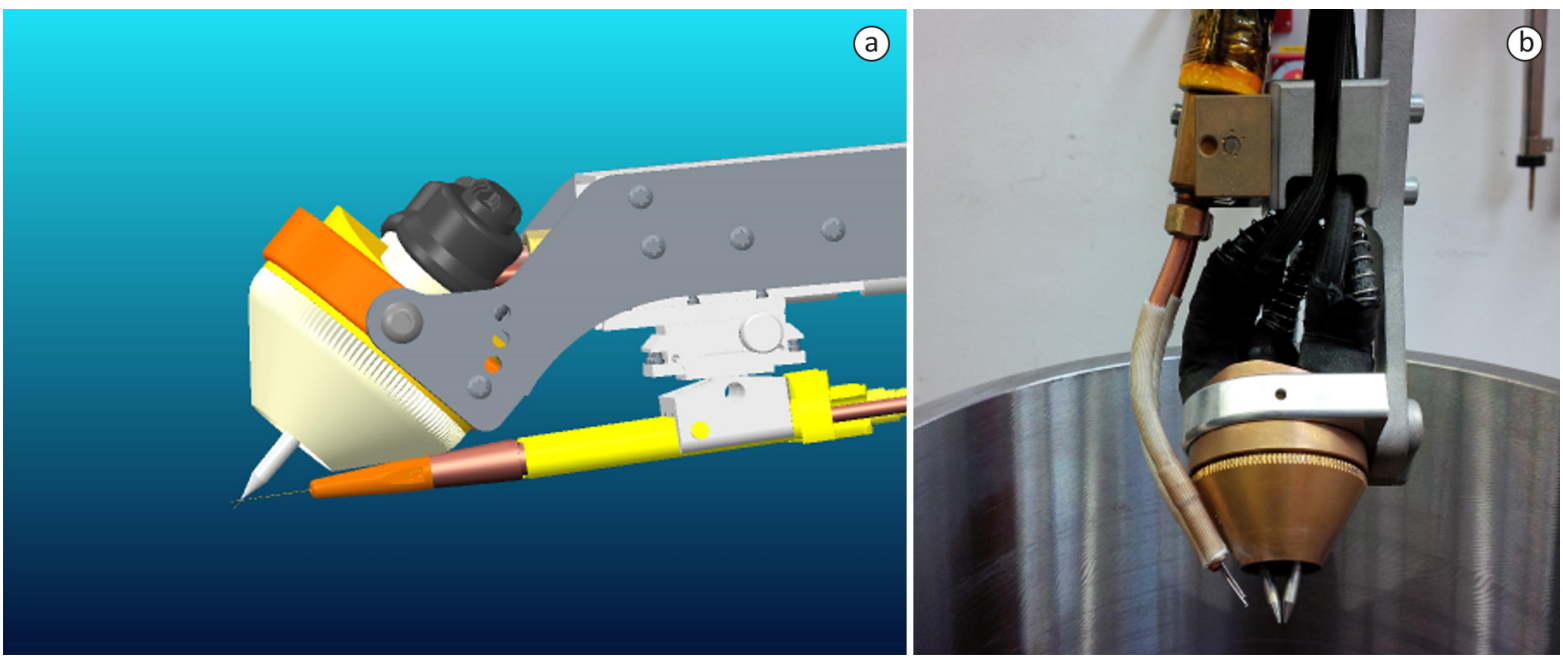

Figure 6. (a) Schematic single- and (b) real part twin-hot-wire dual-cathode welding torch (FRONIUS SpeedClad ${ }^{\circledR}$ ).

\subsection{System configuration}

Adequately assembled the system shall allow for single- and twin-hot-wire weld cladding application. Figure 7a schematically depicts the configuration for performing the former and Figure $7 \mathrm{~b}$ the latter.
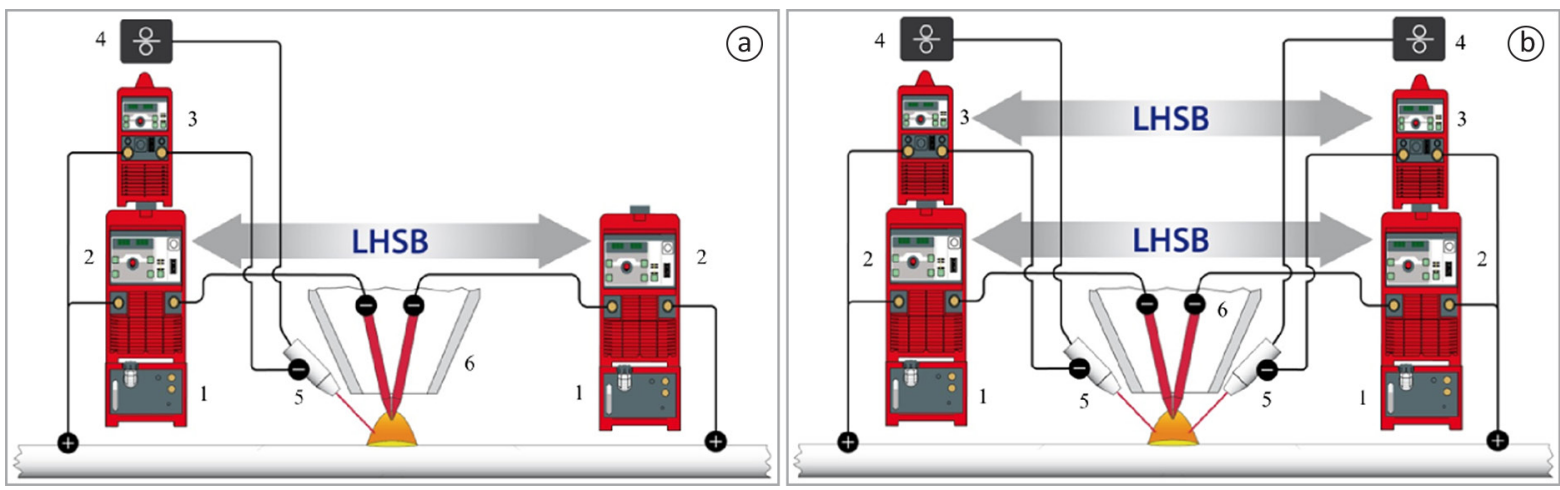

Figure 7. Schematic dual-cathode single-hot-wire (a) and (b) twin-hot-wire GTA weld clad system configuration $\left(\right.$ SpeedClad $\left.{ }^{\circledR}\right)$. Note that $1=$ chiller; $2=$ GTAW inverter power supply; $3=$ hot-wire inverter power supply; 4 = wire feeder; 5 = hot-wire contact tube; 6 = dual-cathode torch. 
Process mode and stability relevant components are interacting via hardware 'Local High Speed Bus' (LHSB) interface, permitting to employ both pure constant direct current or to superimpose and synchronise current and wire feed motion. Both is of crucial importance in performing smooth start/stop sequences. In its practical configuration, equipped to an ETR ${ }^{\circledR}$ column and boom system, the device physically appears as schematically depicted in Figure 8. The figure also shows the superimposed system controller, allowing for sophisticated determination of weld paths to follow, according to the design of the part of interest.

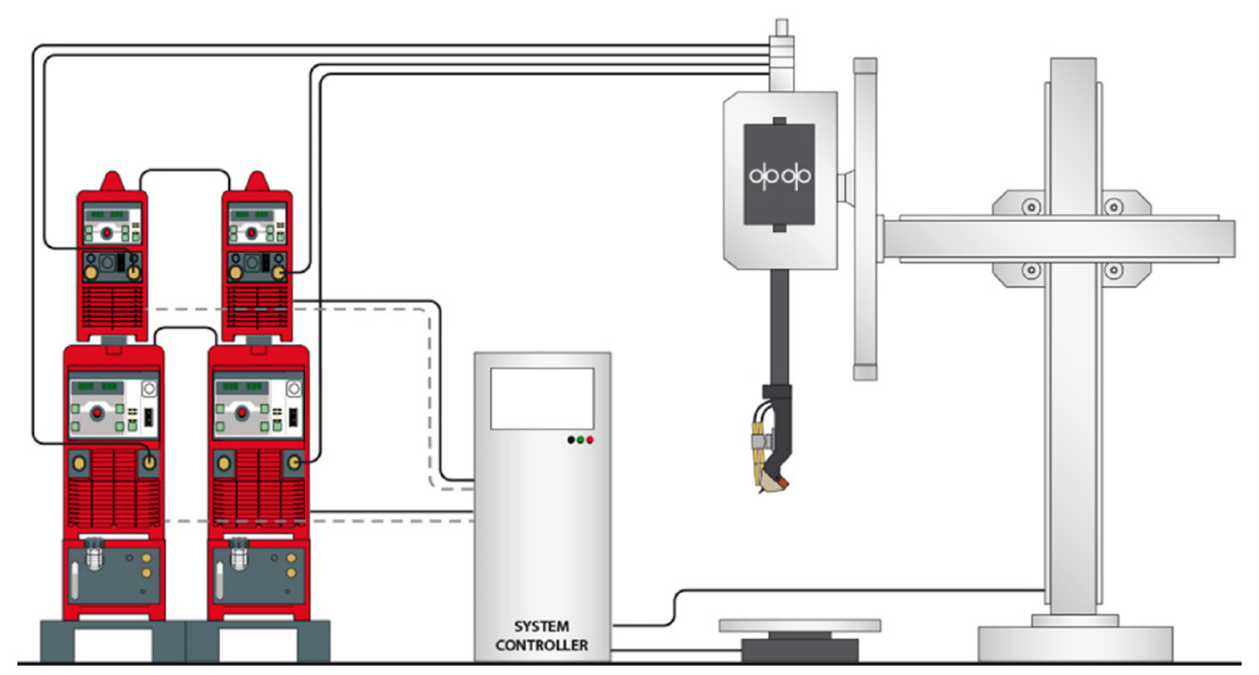

Figure 8. Schematic dual-cathode GTA weld clad system (SpeedClad ${ }^{\circledR}$ ).

\section{Experimental}

Given the novel dual-cathode GTA weld cladding process and the equipment available it was attempted to quantify differences and, if possible, to evaluate technological benefits to other weld overlay process variants. It needs mention that a distinct experimental approach was originally taken for achieving preliminary results. That is. Single- and dual-cathode both twin- and single wire weld cladding was conducted in the welding position easiest to apply; i.e. 'PA' (AWS ' $1 F^{\prime}$ '). Subsequently to that the experimental conditions (e.g. welding position) were tangibly aggravated for testing the novel advanced dual-cathode GTAW clad process. Subsequently the experimental conditions for the application of the dual-cathode GTA weld cladding process were exacerbated, thereby to prove applicability given the regular industrial environment. Results were compared to each other and the quantitative differences summarised.

\subsection{Single-cathode twin-hot-wire GTA weld cladding}

Substrate weld specimens were produced from low carbon grade parent metal S235 JR (acc. to Euronorm EN 10025) and $50 \mathrm{~mm}$ thickness. Surface was milled and cleaned applying ethyl alcohol prior to welding-subsequently conducted without preheating. Regular commercial FRONIUS systems and components have been applied; i.e. 'Magic Wave 5000' AC/DC GTAW inverter (500 A-40\% duty cycle) and, for hot-wire cladding, a 'Transtig 2200 JOB' GTAW inverter (weld current 220 A-40\% duty cycle) have been used as power supplies. A 6-axis KUKA articulated robot equipped with $4.5 \mathrm{~m}$ hose package + water-cooled 'TTW 4500' welding torch and a superimposed 'HMI-T10CC' system control unit were used for arc motion and process control, respectively. Argon (purity 99.996\%) as the shielding gas at a flow rate of $12 \mathrm{slmin}^{-1}$ and a $2 \%$ cerium-oxide doped $\varnothing 3.2 \mathrm{~mm}$ tungsten electrode ground to $60^{\circ}$ included angle, were applied. Filler wire in both trial series was $\varnothing 1.2 \mathrm{~mm}$ nickel base alloy UNS N06625 (AWS ER NiCrMo-3) 'Böhler Nibas 625-IG'. Filler metal specific density was $8.44 \mathrm{gcm}^{-3}$ [27].

All processes; i.e. single-cathode cold- and hot-wire as well as dual-cathode twin hot- wire cladding were performed applying 2-layer and targeting at an average layer thickness of $\sim 2.5 \mathrm{~mm}$. According to industrial demands the metallurgical quality of the second clad layer was evaluated through its iron content related to a 
specific distance from its surface. That is, $\leq 55 \%$ Fe at $\leq 3.0 \mathrm{~mm}$ below the surface had to be consistently proved for meeting the requirements.

\subsection{Single-cathode twin-hot-wire and dual-cathode single-hot-wire GTA weld cladding}

Table 2 states the preliminarily conducted weld trials, using pulsed and constant straight polarity weld current.

Table 2. Preliminary trials matrix.

\begin{tabular}{|c|c|c|c|c|c|}
\hline $\begin{array}{l}\text { Single-cathode } \\
\text { twin-hot-wire }\end{array}$ & & $\begin{array}{l}\text { Single-cathode } \\
\text { twin-hot-wire }\end{array}$ & & $\begin{array}{l}\text { Dual-cathode } \\
\text { single-hot-wire }\end{array}$ & \\
\hline Pulse current $I_{p}[A]$ & 320 & Pulse current $I_{p}[A]$ & 350 & Weld current $(I)[\mathrm{A}]$ & $450^{*}$ \\
\hline Background current $I_{b}[A]$ & 280 & Background current $I_{b}[A]$ & 300 & Background current $I_{b}[A]$ & - \\
\hline Mean voltage (U) $[\mathrm{V}]$ & 13.5 & Mean voltage $(\mathrm{U})[\mathrm{V}]$ & 14.2 & Mean voltage $(\mathrm{U})[\mathrm{V}]$ & 12.1 \\
\hline Wire feed rate $\mathrm{mmin}^{-1}$ & $1.6^{*}$ & Wire feed rate $\mathrm{mmin}^{-1}$ & $2.6^{*}$ & Wire feed rate $\mathrm{mmin}^{-1}$ & 7.6 \\
\hline Travel speed $\left[\mathrm{cmmin}^{-1}\right]$ & 32 & Travel speed $\left[\mathrm{cmmin}^{-1}\right]$ & 50 & Travel speed $\left[\mathrm{cmmin}^{-1}\right]$ & 80 \\
\hline Pulse time $\left(t_{p}\right)[\mathrm{ms}]$ & 200 & Pulse time $\left(t_{p}\right)[\mathrm{ms}]$ & 150 & Pulse time $\left(t_{p}\right)[\mathrm{ms}]$ & - \\
\hline Background time $\left(t_{b}\right)[\mathrm{ms}]$ & 200 & Background time $\left(t_{b}\right)[\mathrm{ms}]$ & 150 & Background time $\left(t_{b}\right)[\mathrm{ms}]$ & - \\
\hline Frequency $[\mathrm{Hz}]$ & 2.5 & Frequency $[\mathrm{Hz}]$ & 3.3 & Frequency $[\mathrm{Hz}]$ & - \\
\hline Hot wire current $I_{h}[\mathrm{~A}]$ & 70 & Hot wire current $I_{h}[\mathrm{~A}]$ & 70 & Hot wire current $I_{h}[\mathrm{~A}]$ & 190 \\
\hline
\end{tabular}

*Note that these data represent total values; i.e. require division by 2 .

\subsection{Dual-cathode twin hot-wire GTA weld cladding}

A commercial FRONIUS ETR ${ }^{\circledR}$ GTAW cladding system, similar to Figure 8, was used comprising a 'FCB 3000-3000/ML 700' Column and Boom paired with 'FCS 200-1000/ML 375' cross slide and the novel 'TTHW 6000 M SpeedClad ${ }^{\circledR}$, GTAW twin-hot-wire torch. The system was completed assembling 2 DC GTAW power supplies (Transtig 5000 JOB〉 (500A-40\% duty cycle) and 2 hot-wire power supplies (Transtig 2200 JOB〉, as well as a superimposed system control unit FRONIUS «FPA 9000».

Tube weld specimens of diameter $155 \mathrm{~mm}$ and wall thickness $20 \mathrm{~mm}$, to simulate internal borehole cladding, were produced from low carbon S $235 \mathrm{JR}$ parent metal. 30 beads were deposited in total applying weld position (PC) (AWS $\langle 2 F\rangle)$. Specimen surfaces were machined and cleaned using ethylene alcohol prior to welding. Consumables were similar to single-cathode hot-wire GTA weld cladding; i.e. $\varnothing 1.2 \mathrm{~mm}$ UNS N06625 filler wire and argon was the shielding gas (purity 99.996\%). Gas flow rate was digitally controlled at $24 \mathrm{slmin}^{-1}$ and $2 \%$ cerium-oxide doped $\varnothing 4.0 \mathrm{~mm}$ tungsten electrodes were used, ground to obtain $56^{\circ}$ included angle. Circumferential weld bead deposition was conducted employing $3.4 \mathrm{~mm}$ vertical lateral increment and electrode gap was maintained constant deploying a regular arc voltage control (AVC) included in the ETR ${ }^{\circledR}$ system. Parts were manually preheated to $200{ }^{\circ} \mathrm{C}$ using oxyfuel torch $\left(\mathrm{C}_{3} \mathrm{H}_{8}+\mathrm{O}_{2}\right)$. Interpass temperature was chosen $200{ }^{\circ} \mathrm{C}$. For the dual-cathode twin-hot-wire welds Table 3 depicts a WPS excerpt of the essential variables used.

Table 3. Dual-Cathode (FRONIUS SpeedClad ${ }^{\circledR}$ ) twin-hot-wire weld trial matrix.

\begin{tabular}{lclc}
\hline \multicolumn{1}{c}{ DC constant } & & \multicolumn{1}{c}{ DC pulsed } \\
Weld current $(I)[\mathrm{A}]$ & $\mathbf{3 7 0}$ & Pulse current $\left(I_{p}\right)[\mathrm{A}]$ & $\mathbf{4 3 0}$ \\
Background current $\left(I_{b}\right)[A]$ & - & Background current $\left(I_{b}\right)[A]$ & $\mathbf{3 7 0}$ \\
Mean voltage $(U)[\mathrm{V}]$ & $\mathbf{1 0 . 4}$ & Mean voltage $(U)[\mathrm{V}]$ & $\mathbf{1 1 . 0}$ \\
Wire feed rate $\left[\mathrm{mmin}^{-1}\right)$ & $\mathbf{4 . 8}$ & Wire feed rate $\left[\mathrm{mmin}^{-1}\right)$ & $\mathbf{5 . 0}$ \\
Weld travel speed $\left[\mathrm{cmmin}^{-1}\right]$ & $\mathbf{1 2 0}$ & Weld travel speed $\left[\mathrm{cmmin}^{-1}\right]$ & $\mathbf{1 2 0}$ \\
Pulse time $\left(t_{p}\right)[\mathrm{ms}]$ & - & Pulse time $\left(t_{p}\right)[\mathrm{ms}]$ & $\mathbf{7 0}$ \\
Background time $\left(t_{b}\right)[\mathrm{ms}]$ & - & Background time $\left(t_{b}\right)[\mathrm{ms}]$ & $\mathbf{7 0}$ \\
Frequency $[\mathrm{Hz}]$ & - & Frequency $[\mathrm{Hz}]$ & $\mathbf{7 . 1}$ \\
Hot wire current $I_{h}[\mathrm{~A}]$ & $\mathbf{2 4 0}$ & Hot wire current $I_{h}[\mathrm{~A}]$ & $\mathbf{2 5 0}$ \\
\hline
\end{tabular}


Table 3 reveals that both wire feed rate to hot-wire current ratio and weld travel speed have been maintained constant throughout both trial series. In pulsed welding the ratio between pulsed and background cycle defines the height of the output current. Adjusting background and pulsed current time balanced to each other and given the parameters chosen the pulsed process shows slightly higher mean weld current.

\section{Results}

\subsection{Single- cathode (twin-wire) and dual-cathode (single-wire)}

Figure 9a-c show the macro-sections for the single-cathode twin wire and dual-cathode single-wire weld clad sequences.
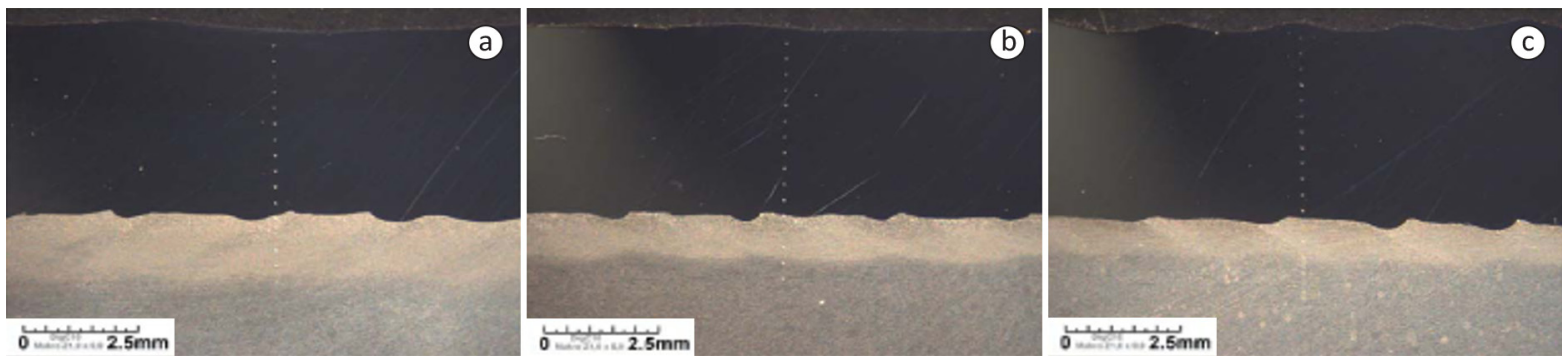

Figure 9. Macro-section for single-cathode twin-hot-wire at $32 \mathrm{cmmin}^{-1}$ (a); $50 \mathrm{cmmin}^{-1}$ (b) and dual-cathode single-hot-wire; (c) at $80 \mathrm{cmmin}^{-1}$ weld travel speed.

No significant visual variation appears in the penetration profile between pulsed single-cathode twin-wire and constant straight polarity DC dual-cathode single wire clad sequence. Fe-content were found safely below $5 \%$ for all three welds. Deposition rates achieved were respectively $1.83 \mathrm{kgh}^{-1}\left(32 \mathrm{cmmin}^{-1}\right)$ and $2.98 \mathrm{kgh}^{-1}\left(50 \mathrm{cmmin}^{-1}\right)$ for single-cathode twin-wire, and $4.23 \mathrm{kgh}^{-1}\left(80 \mathrm{cmmin}^{-1}\right)$ for dual-cathode single-wire GTA weld cladding.

\subsection{Dual-cathode (twin-wire) constant and pulsed straight polarity direct current}

Figure 10a as an overview reveals the compact dual-cathode head processing inside the $\varnothing 155 \mathrm{~mm}$ pipe specimen and (b) shares an idea of high surface layer quality obviously achieved applying this novel method.
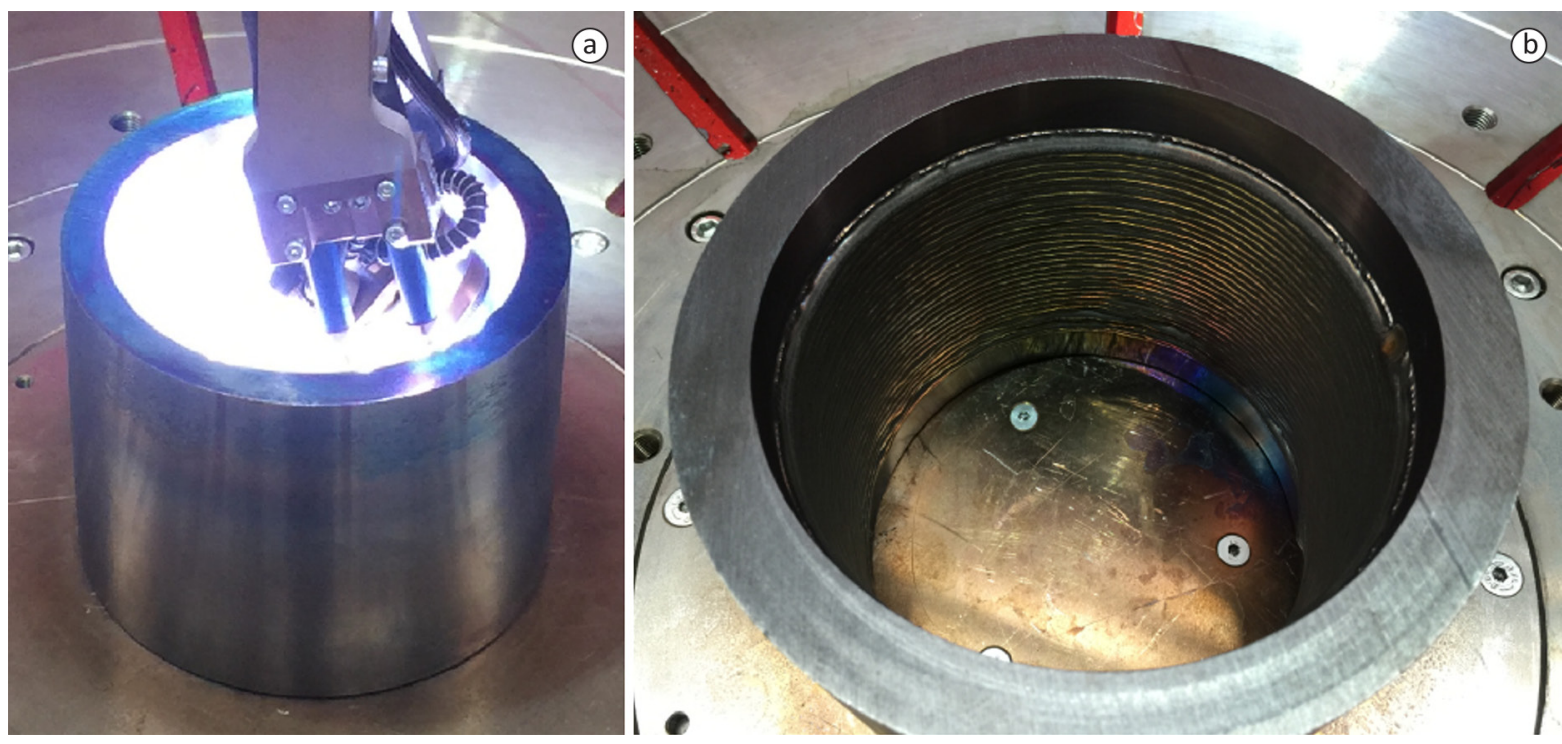

Figure 10. (a) Dual-cathode (SpeedClad ${ }^{\circledR}$ ) head during cladding operation and (b) deposited pulsed process clad layers. 
According to the parameter matrix depicted in Table 3, Figure 11a, b represents the macro-sections of dual-cathode weld clad trials as subjected to EDX-analysis.
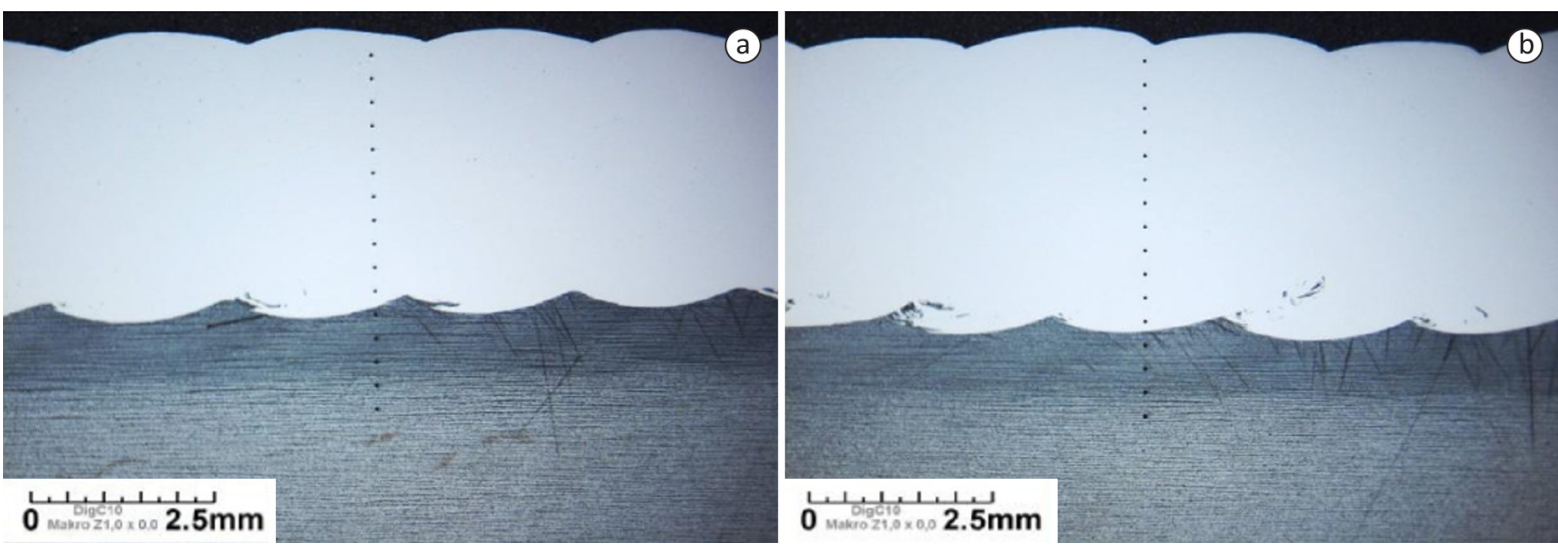

Figure 11. Dual-cathode twin-hot-wire macro-section for constantly supplied direct current (a) and pulsed direct current (b) at weld travel speed $120 \mathrm{cmmin}^{-1}$ and welding position 'PC'.

For all weld sequences Figure 12 shows the clad quality indicating Fe-content over the distance of $3.0 \mathrm{~mm}$ below the layer surface, measured employing EDX analysis (System: Oxford Inca Energy / PM 55). Weld deposition rates employing dual-cathode twin-hot-wire were found considerably increased, respectively leading to $\sim 5.6 \mathrm{kgh}^{-1}$ for constant straight polarity DC and $\sim 5.7 \mathrm{kgh}^{-1}$ for pulsed straight polarity DC. Greater homogeneity is found for higher current - higher travel speed trials. However, the lowest travel speed of $32 \mathrm{cmmin}^{-1}$ is prone to greater noise in the surface elemental distribution.

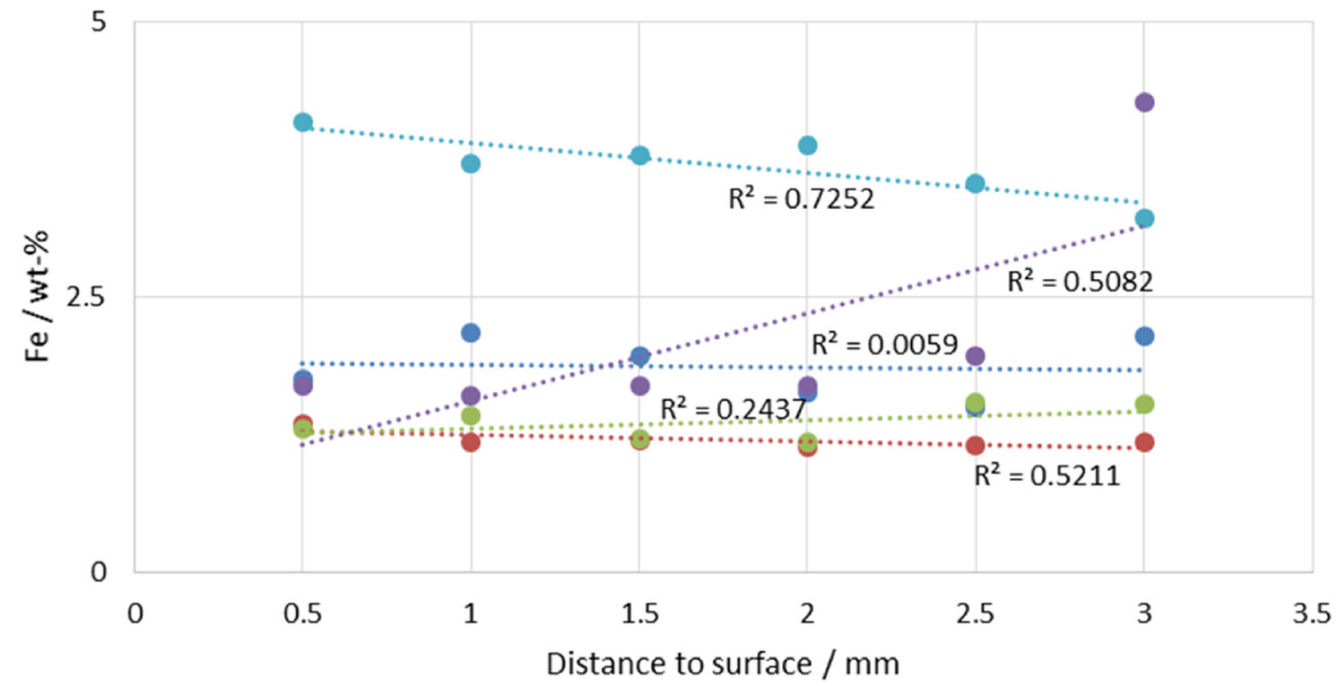

\begin{tabular}{|c|c|c|c|}
\hline$\bullet$ & Single-Cath. Twin-Hot-Wire $32 \mathrm{cmmin}-1$ & - & Single-Cath. Twin-Hot-Wire $50 \mathrm{cmmin}-1$ \\
\hline - & Dual-Cath. Single-Hot-Wire $80 \mathrm{cmmin}-1$ & $\bullet$ & Dual-Cath. Dual-Hot-Wire_Constant_DC $120 \mathrm{cmmin}-1$ \\
\hline$\bullet$ & Dual-Cath. Dual-Hot-Wire_Pulsed_DC $120 \mathrm{cmmin}-1$ & .......... & - Linear (Single-Cath. Twin-Hot-Wire $32 \mathrm{cmmin}-1$ ) \\
\hline$\cdots \cdots \cdots$ & Linear (Single-Cath. Twin-Hot-Wire $50 \mathrm{cmmin}-1$ ) & .......... & - Linear (Dual-Cath. Single-Hot-Wire $80 \mathrm{cmmin}-1$ ) \\
\hline ........... & Linear (Dual-Cath. Dual-Hot-Wire_Constant_DC $120 \mathrm{cmmin}-1$ ) & .......... & - Linear (Dual-Cath. Dual-Hot-Wire_Pulsed_DC $120 \mathrm{cmmin}-1$ ) \\
\hline
\end{tabular}

Figure 12. Fe-content as a function of process applied and distance below clad layer surface. 
Figure 13 represents from EDX analysis the elemental surface layer chemistry focusing on the essential alloying elements particularly in charge of the deposited clad layer corrosion resistance. Also, for comparison, it involves the analysis of the filler wire employed. Similar elemental distribution can be found in the second layer especially in using the novel dual-cathode twin-hot-wire GTAW clad method, with minimal differences to the consumable chemistry, exceptionally, of course, the Fe-content deliberately decreased in the wire.

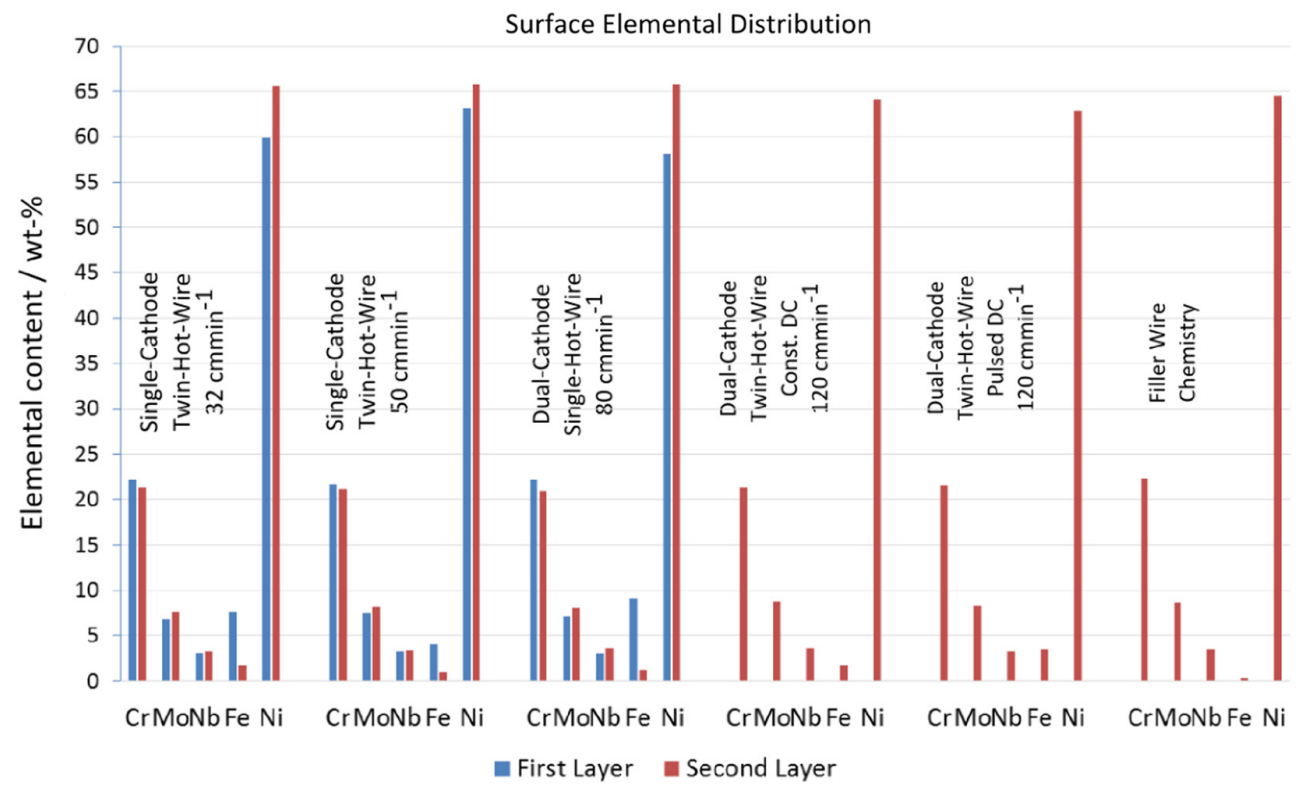

Figure 13. Elemental distribution at clad layer surface compared with filler wire chemistry. Note analysis for dual-cathode twin-wire conducted only for the second layer.

Based upon theoretical considerations on varying impacts depending maybe on varying orientation angles of the dual-cathode; i.e. from longitudinal to normal related to weld progression, additional studies were conducted using the dual-cathode system for both cases. As already investigated and numerically modelled by Leng et al. [23] tangible differences could be approved.

Figure 14a shows the macro-section for the former configuration; i.e. tungsten electrodes arranged longitudinally to weld direction, while Figure $14 \mathrm{~b}$ indicates the electrodes twisted by $90^{\circ}$ to obtain them arranged normal to weld progression.
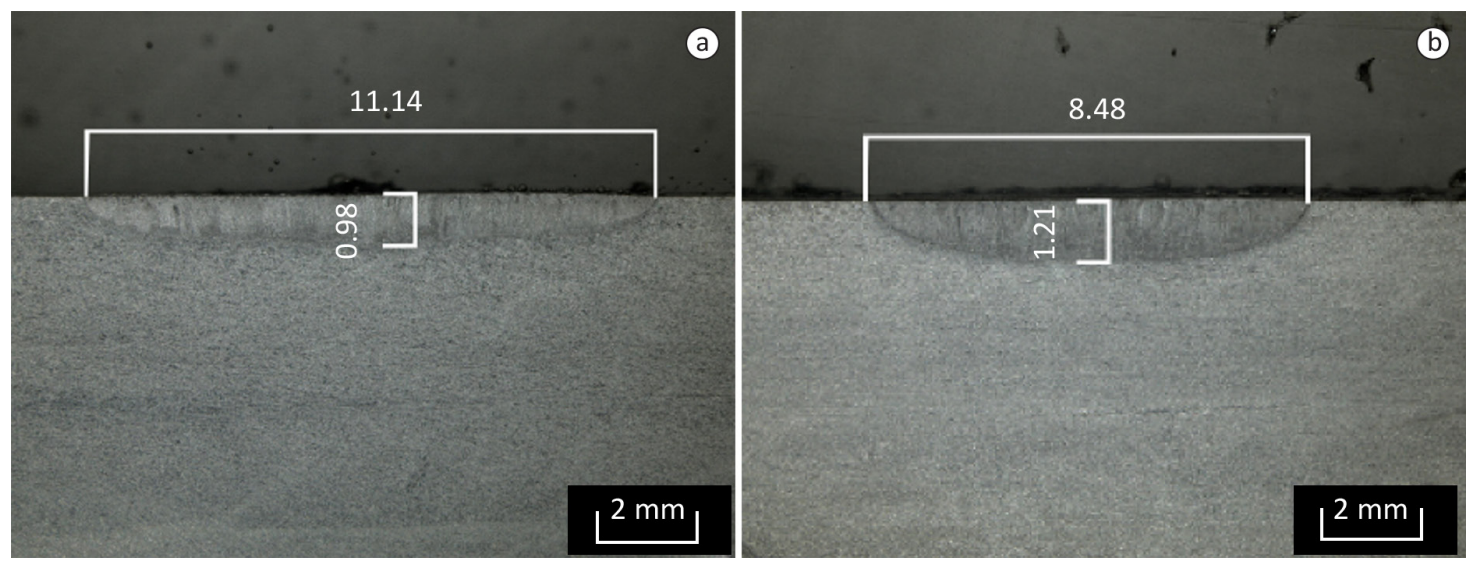

Figure 14. Dual-cathode GTAW autogenously employed with electrodes adjusted longitudinal (a) and normal to weld direction (b). Note, cathode diameter $=4.0 \mathrm{~mm}$; total weld current $=300 \mathrm{~A}(2 \times 150 \mathrm{~A})$; cathode clearance $\sim 2.0 \mathrm{~mm}$; electrode to work distance $=4.0 \mathrm{~mm}$ and weld travel speed $=40 \mathrm{cmmin}^{-1}$. 
The effective influence between both setups can be readily noticed. It is suggested necessary as such to further devote effort in establishing reliable quantitative data on the influence of differently twisted electrodes related to weld metal dilution and elemental distribution.

\section{Discussion}

The results achieved from the experiments accomplished are suggested valuable due to allowing for quantitatively comparing regular high performance GTAW clad processes; i.e. GTAW twin-hot-wire with a novel approach referred to as dual-cathode GTAW.

The latter can be either used employing a single or two filler wires leading to significantly higher deposition rates. The weld trial matrices chosen, distinguished in a preliminary phase using a dual-cathode prototype equipment and a final period particularly focusing on industrial application and targeted at achieving meaningful assessment on process performance and quality aspects to meet, are supposed showing the investigations of other researchers approved.

Although focusing on fusion welding multiple cathode GTAW has been investigated by e.g. Norrish [21], Yamada [18,19] and Kobayashi et al. [20]. However, we could find the novel developed method also capable of increasing weld travel speed, as to overcome weld defects and rising productivity in GTA weld cladding. Yet outstanding in quantitative approval and hence only qualitatively suggested at this stage, we suppose that the fundamental mechanism of both low dilution and eliminating weld defects (undercut) arises from a lower arc pressure at the same total current vs. single-cathode welding, connected to the specific cathode arrangement in the welding head developed. It needs mention though that the results derived by other researchers considerably differ to each other. That is Kobayashi et al. [20] found respectively arc pressures of 1500 Pa for a single cathode (200 A weld current $+2 \mathrm{~mm}$ "arc length") and 250 Pa for their dual-cathode arrangement; for the same total current and similar experimental setup Zhang et al. [22] and Leng et al. [23] determined maximum arc pressures of $\sim 500 \mathrm{~Pa}$ (single-cathode) and $\sim 95 \mathrm{~Pa}$ (dual-cathode).

Apart from these differences we nonetheless suggest the relationship between weld current height and arc pressure, as e.g. postulated by Adonyi et al. [15] and Rokhlin and Guu [16], also applicable to GTAW hot-wire weld cladding; at least for the experimental conditions described in this paper. This is due to the higher dilution ratios observed when charging the dual-cathode arrangement with pulsed direct current (thereby increasing the mean current) vs. constantly applied straight polarity direct current.

Despite achieving a higher mean current the weld deposition rate was found relatively little raised with the pulsed sequence, which is suggested explainable by the only slightly increased wire feed rate vs. the constant current sequence $\left(5.0 \mathrm{mmin}^{-1} \mathrm{vs} .4 .8 \mathrm{mmin}^{-1}\right)$. Considering further dilution ratios - found raised for pulsed current GTAW - and correspondingly the constant ratio between wire feed rate and hot-wire current one may suggest though the results from Shinozaki et al. [14] as approved; supposing that filler wire melting is mainly influenced by the hot-wire current instead of being a function of the arc current. However, we suggest that further work appears required in this conjunction to assess both these assumptions as well as evaluating the relationship between wire feed rate, hot-wire current and arc current.

Given our experiments, see Figure 14; i.e. changing the dual-cathode orientation angle related to weld progression, we suggest the considerations of Leng et al. [23] on varying current density and temperature fields around the cathodes, valuably contributing to future research, especially in connection to dual-cathode twin-hotwire GTA weld cladding. Hence, and although not yet practically proved by the investigations dealt with in this paper, it is supposed that both weld dilution and deposited weld bead height can be positively affected incorporating the dual-cathode orientation angle, hereby further to improve weld metal elemental distribution and secondary properties, e.g. clad layer corrosion resistance.

\section{Conclusions}

From the experiments explained in this paper we can draw the following conclusions: 
- Single-cathode gas tungsten arc (GTA) hot-wire weld cladding employing two wires of $\varnothing 1.2 \mathrm{~mm}$ and typical UNS N06625 chemistry was found reliably leading to weld results safely meeting industrial requirements.

- A novel dual-cathode gas tungsten arc welding (GTAW) system was compared with the results obtained from single-cathode GTA weld cladding.

- The novel system was proved capable of considerably raising weld performance; i.e. weld deposition rate and weld travel speed, and nonetheless to safely meet all industrial requirements.

- Fe-content, as the qualitative indicator for clad layer quality, was quantified reliably remaining below threshold when employing the dual-cathode GTA weld clad system both single-wire (weld position 'PA') and twin-wire (weld position ' $\mathrm{PC}$ ').

- The relationship between weld current height and arc pressure appears approved and applicable also to an experimental setup as used in this investigation.

- Although not quantitatively approved in this investigation the reduced arc pressure is supposed the major factor in dropping the depth of penetration when employing dual-cathode GTA weld cladding, hereby considerably reducing the dilution ratio vs. single-cathode GTA weld cladding of similar amount of weld current.

- Hot-wire current is suggested mainly affecting weld deposition rate vs. arc current and as such our results appear to confirm the findings of other researchers.

- Experimental results on varying dual-cathode orientation angle related to weld progression (longitudinal or normal) are suggested approving theoretical considerations of other researchers and are considered valuable for future work.

- Dual-cathode GTAW is supposed finally to future sustainably and reliably broadening the range of high-quality weld cladding applications required complying with 'zero-defect' criteria.

\section{Acknowledgements}

The authors are grateful to Mr Emre Güneruz, Mr Franz Bichler and Mr Andreas Bauer, all with FRONIUS International, who have performed the experimental work; as well as to Mr Uwe Kroiss of FRONIUS International's $R \& D$ department, for conducting the dual-cathode orientation trials.

\section{References}

[1] Egerland S. Controlled GMA welding processes prove applicability for high-quality weld overlay. In: Proceedings of the Welding and Repair Technology for Power Plants: 9th International EPRI Conference; 2010 June 23-25; Fort Myers. Palo Alto: Electric Power Research Institute; 2010.

[2] Egerland S. Status and perspectives in overlaying under particular consideration of sophisticated welding processes. Quarterly Journal of the Japan Welding Society. 2009;27(2):50s-54s.

[3] Egerland S, Helmholdt R. Overlaying (cladding) of high temperature affected components by using the cold metal transfer process. In: Mayr P, editor. Safety and Reliability of Welded Components in Energy and Processing Industry. Austria: Verlag der Technischen Universität Graz; 2008. p. 327-332.

[4] Freeman ND, Manz AF, Saenger JF Jr, Stanchus FT, inventors; Union Carbide Corp, assign. Method for depositing metal with a TIG arc. United States patent US 3483354. 1969 Dec 9.

[5] Manz AF, Norman R, Wroth RS, inventors; Union Carbide Corp, assign. Electric arc working with hot wire addition. United States patent US 3163743. 1964 Dec 29.

[6] Manz AF, inventors; Union Carbide Corp, assign. Consumable electrode arcless electric working. United States patent US 3122629A. 1964 Feb 25.

[7] Hori K, Myoga T, Shinomiya M, Eiji W, Kazuki K, Toshiaki T et al., inventors; Kaisha BHK, assign. Semi-automatic hot wire TIG welding equipment. United States patent US 4801781. 1989 Jan 31 .

[8] Mizuno T, Shimizu T, inventors; Kaisha MDK, assign. Hot wire welding system. United States patent US 4464558A. 1984 Aug 7.

[9] Goldsberry C. Hot-wire TIG: not new but gaining appeal [web page]. [access in 3 oct. 2015]. Cleveland: Welding Design \& Fabrication; 2007. Available from: http://weldingdesign.com/ archive/hot-wire-tig-not-new-gaining-appeal.

[10] Manabe Y, Wada H, Zenitani S, Hiromoto Y, Hashimoto Y. Investigation on TIG welding using 2 filler wires with electromagnetically controlled molten pool process in horizontal position. Quarterly Journal of the Japan Welding Society. 2000;18(1):40-50. http:// dx.doi.org/10.2207/qjjws.18.40.

[11] Hori K, Watanabe H, Myoga T, Kusano K. Development of hot wire TIG welding methods using pulsed current to heat filler wire: research on pulse heated hot wire TIG welding processes. Welding International. 2004;18(6):456-468. http://dx.doi. org/10.1533/wint.2004.3281.

[12] Ueguri S, Tabata Y, Shimizu T, Mizuno T. A study on control of deposition rate in hot-wire TIG welding. Quarterly Journal of the Japan Welding Society. 1986;4(4):678-684. http://dx.doi. org/10.2207/qjjws.4.678. 
[13] Yamamoto M, Shinozaki K, Myoga T, Kanazawa T, Arashin H. Development of ultra-high-speed GTA welding process using pulse-heated hot-wire. In: Pre-Prints of the 82nd National Meeting of JWS. Tokyo: Japan Welding Society; 2008. p. 228-229.

[14] Shinozaki K, Yamamoto M, Nagamitsu Y, Uchida T, Mitsuhata K, Nagashima T, et al. Melting phenomenon during ultra-high-speed GTA welding method using pulse-heated hot-wire. Quarterly Journal of the Japan Welding Society. 2009;27(2):22s-26s. http:// dx.doi.org/10.2207/qjjws.27.22s.

[15] Adonyi Y, Richardson R, Baeslack W. Investigation of arc force effects in subsurface GTA welding. Welding Journal. 1992;71(9):321s-330s.

[16] Rokhlin S, Guu A. A study of arc force, pool depression, and weld penetration during gas tungsten arc welding. Welding Journal. 1993;72(8):381s-390s

[17] Mendez P, Eagar T. Penetration and defect formation in highcurrent arc welding. Welding Journal. 2003;82(10):296s-306s.

[18] Yamada M. Development of high efficiency TIG welding method. 1st Report of the Japan Welding Society. 1998;63:24-25.

[19] Yamada M, Tejima A, inventors; Ishikawajima-Harima Heavy Industries Co., assign. TIG welding apparatus and method United States patent US 6982397. 2006 Jan 3.

[20] Kobayashi K, Nishimura Y, lijima T, Ushio M, Tanaka M, Shimamura J, et al. Practical application of high efficiency twin-arc TIG welding method (SEDAR-TIG) for PCLNG storage tank. Welding in the World. 2013;48(7-8):35-39.

[21] Norrish J. Advanced welding processes. Cambridge: Woodhead Publishing; 2006.

[22] Zhang G, Leng X, Lin W. Physics characteristic of coupling arc of twin-tungsten TIG welding. Transactions of Nonferrous Metals Society of China. 2006;16(4):813-817.

[23] Leng X, Zhang G, Wu L. The characteristic of twin-electrode TIG coupling arc pressure. Journal of Physics D, Applied Physics. 2006;39(6):1120-1126. http://dx.doi.org/10.1088/0022 3727/39/6/017.

[24] Maecker H. Plasmaströmungen in Lichtbögen infolge eigenmagnetischer Kompression. Zeitschrift für Physik. 1955;141(1):198-216

[25] Zhang G, Xiong J, Gao H, Wu L. Effect of process parameters on temperature distribution in twin-electrode TIG coupling arc. Journal of Quantitative Spectroscopy \& Radiative Transfer. 2012;113(15):1938-1945. http://dx.doi.org/10.1016/j. jqsrt.2012.05.018

[26] Martins ÉA. Avaliação da soldagem tig autógena duplo cátodo twin Tig [trabalho de graduação]. Florianópolis: Universidade Federal de Santa Catarina; 2010.

[27] Special Metals Corporation. Inconel alloy 625. Special Metals. 2006. Material Manufacturer Data Sheet. 